\title{
Development and Piloting the MMMM Ecological Interactive Open Systems Model: A Prospective One-Year Treatment Outcome of Children of Tortured Refugees
}

\author{
Ibrahim A. Kira' ${ }^{1}$, Linda Lewandowski² ${ }^{2}$ Jeffery S. Ashby ${ }^{3}$, Andrea Z. Omidy ${ }^{4}$ \\ ${ }^{1}$ Center for Cumulative Trauma Studies, Stone Mountain, USA \\ ${ }^{2}$ University of Massachusetts, Amherst, USA \\ ${ }^{3}$ Georgia State University, Atlanta, USA \\ ${ }^{4}$ Boston Medical Center, Boston, USA \\ Email: kiraaref@aol.com
}

Received 15 June 2015; accepted 8 August 2015; published 11 August 2015

Copyright (C) 2015 by authors and Scientific Research Publishing Inc.

This work is licensed under the Creative Commons Attribution International License (CC BY). http://creativecommons.org/licenses/by/4.0/

c. (i) Open Access

\section{Abstract}

Children of refugee torture survivors present a compelling case of cumulative and continuous chronic past and current traumas and complex post-cumulative trauma symptoms. Traditional models of interventions with victims of single past traumas may not be effective with such victims. The goal is to develop and initially test a new open multi-systemic, multi-component and multimodal intervention model (MMMM) as applied in the context of Summer Day Treatment and After School (SDTAS) program, and to determine its potential effectiveness as well as the feasibility of a larger study with more rigorous experimental design. A total of 27 secondary torture survivor Iraqi refugee children (13 males and 14 females, age between 11-16), living in the US, who suffered from serious symptoms and were non-responsive to treatment as usual for at least the previous six months, completed the planned interventions and three times follow-up assessments of five domains: PTSD, complex PTSD, anxiety, depression, and global level of functioning (GAF). Repeated measure analysis of variance was used to analyze changes over the three time points. Results indicated significant decrease in symptoms, and increased GAF with high effect sized (Partial Eta Squared ranged between 0.85 - 0.93). The amount of change displayed by the treated individuals was large enough to be clinically meaningful. Current study provides evidence of potential effectiveness of this novel intervention and of the feasibility of more rigorous and larger future controlled clinical trials to help develop evidence-based treatments for the multiply traumatized children who suffer past and present ongoing adversities. We suggest that the model is cost effective, and can be conducted with children of torture survivors and refugees in different settings world-wide by professionals or by trained supervised para-professionals. 
Keywords

Torture Survivors' Children, Cumulative Trauma, Ecological Model of Recovery, Treatment
Outcome, Current, Continuous, and Cumulative Trauma-Focused Cognitive Behavior Therapy
CCC-TF-CBT

\section{Introduction}

\subsection{Critique for the Current Intervention Models and the Need for New Clinical Paradigm}

The current focus on PTSD as the only post-trauma recognizable disorder is questionable. The mental health effects of different trauma types, their cumulative and proliferation effects go beyond PTSD to other comorbid or distinct different diagnoses (Kira, 2001). For example a recent study found that $26 \%$ of survivors of the $9 / 11$ attacks developed a new major depressive disorder episode that was significantly more prevalent than 9/11-related PTSD (14\%) (North et al., 2015). The study concluded that distinct mechanisms underlying these two disorders are differentially related to the direct exposure to trauma.

Further, the co-occurrence of multiple psychiatric disorders in clients, especially who are multiply traumatized, is so prevalent that it may be the rule, not the exception (e.g., Kessler, Chiu, Demler, \& Walters, 2005; Chu, Merson, Zandberg, \& Areizada, 2012). These high rates of comorbidity have presented several challenges to the current conceptualization of mental disorders as discrete diagnostic categories. The interactive effects between comorbid disorders are likely to exist (e.g., Keeley, Chmielewski, \& Bagby, 2015). Many researchers have argued that diagnostic overlap may be a meaningful "signal" which can inform models of psychopathology (e.g., Krueger \& Markon, 2006). The profiles of diagnostic comorbidity may represent underlying dimensions. Empirical studies found that psychopathology syndromes are hierarchically constructed and represent a general psychopathology factor, with specific three factors for internalizing, externalizing and psychotic dimensions (e.g., Caspi et al., 2014, Laceulle, Volleberge, \& Ormel, 2015). These dimensions and the underlying dynamics may be addressed by relevant transdiagnostic interventions. Further, high comorbidity levels are a result of different dynamics, related to poly-traumatization, such as cumulative and proliferation trauma dynamics.

Furthermore, most of the current trauma-focused treatment models were designed on addressing single past traumas, for example sexual abuse or car accident, and were guided by limited trauma framework. One of the potential problems with the current status of trauma-focused interventions (e.g., Kira, 2010; Kira et al., 2010, 2013, 2014; Bracken, Giller, \& Summerfield, 1997; Summerfield, 1999) is their failure to address important traumatization dynamics, i.e., proliferation and accumulation dynamics. While proliferation indicates that independent trauma can result in several dependent traumas (for example loss of a job due to discrimination) (Pearlin, Aneshensel, \& Leblanc, 1997), cumulative dynamics refer to the cumulative effects of different traumas and stressors across situations or life course. When enough stress and trauma factors accumulate and outweigh the developmental assets or protective factors, or cross the threshold of the individuals' distress tolerance, then different profiles of post-trauma spectrum disorders may develop that may involve comorbid PTSD and other psychiatric or substance abuse disorders. While a dose-response model (the change in effect caused by differing levels of exposure) describes linear traumatogenic dynamics, the cumulative trauma model proposes, additionally, different cumulative non-linear dynamics that surpass the threshold of distress tolerance (e.g., Altshuler, 1981; Kira et al., 2014; Tong, 1978; Zhang, Wang, \& Zhul, 2014).

Additionally, current trauma frameworks and trauma-focused treatment paradigms with minorities, refugees and their children that ignore discriminations as chronic ongoing traumatic stress and its serious effects are problematic. Discrimination and oppression negatively and severely impacts general well-being, self-esteem, self-efficacy, and social relations, as well as mental health (for meta-analysis for their effects on health, see Pascoe \& Smart-Richman, 2009; for the effects of oppression, see Kira et al., 2014). It also increases the Allostatic load and disease (Berger \& Sarnya, 2014). One of the relatively ignored discrimination types that are more prevalent in some refugee cultures is gender discrimination. Gender discrimination found to have salient negative mental health effects in female torture survivors (Kira, et al., 2015; Kira, Ashby, Lewandowski, Smith, \& Odenat, 2012; Kira, Smith, Lewandowski, \& Templin, 2010). Current treatment models with refugees rarely ad- 
dressed this discrimination type.

Studies suggest present- and past-focused interventions that address PTSD and comorbid conditions simultaneously are likely to be more effective, more cost-effective, and more sensitive to patient needs than a single-past trauma-focused approach that target only PTSD (e.g., Hobbs, Kushner, Lee, Reardon, \& Maurer, 2011; Najavits, 2006; Torchalla, Nosen, Rostam \& Allen, 2012).

To conclude, The focus only on single-trauma and only on one related diagnosis, i.e., PTSD may have hindered significant progress in treating especially multiply traumatized, (e.g., refugees, torture survivors, minorities and their children) and in addressing the cumulative and proliferation dynamics of traumatization. While current trauma focused cognitive behavior therapies (TF-CBT) address mostly past Types I (single event, for example car accident) and II traumas (sequence of traumatic episodes, for example sexual abuse), they are often not designed to address current or ongoing adversities, their cumulative and proliferation dynamics and are, as a result, often less effective in addressing Type III (continuous chronic ongoing traumatic stress, e.g., discriminations) and type IV traumas (cumulative traumas), or to de-escalate their proliferation dynamics.

Further, models designed to address ongoing and emerging chronic and traumatic stressors, to address the flux of potential emerging life stressors and adversities, should be dynamic and open, conducted within a flexible structured approach. They should integrate the common therapeutic factors (i.e., therapeutic alliance, counselor expertise and clinical judgment, flexible emergent case conceptualization, and the client's various changing needs and unanticipated current events) (e.g., Laska, Gurman, \& Wampold, 2014). The American Psychological Association (APA) Presidential Task Force on Evidence-Based Practice recommended the inclusion of counselor and client variables as one arm of a multifaceted "portfolio". Effective treatments of more complex trauma would certainly include an emphasis on the therapeutic alliance and the trustworthiness, competence, and perceived expertness of the counselor (or therapeutic team). Relationship factors such as empathy, goal consensus and collaboration, and positive regard, also significantly contribute to the successful outcome of treatments. Case conceptualization in the treatment of more complex traumas is a continuous process of generating hypotheses about causes, antecedents, and maintaining influences for the client's problems. This process informs clinical decision-making and treatment planning throughout the course of treatment from intake to termination.

Furthermore, some of the practices and paradigms commonly used in counseling minorities reinforce, directly or indirectly, the hegemonic practices and paradigms that reflect the social power dynamics that perpetuate discrimination. Goodman \& Gorski, 2015; call to decolonize counseling of minorities through Social Justice and advocacy that challenges the infrastructure of dominance in society, as well as to brave ourselves as clinicians, scholars, and activists to apply our critical consciousness when working with multiply traumatized minority clients (see also Goodman \& West-Olatunji, 2009).

\subsection{A New Trauma Paradigm That Guide Building the New Intervention Model}

To address the gaps in current trauma conceptualizations, Kira and associates proposed a developmental-based trauma framework, DBTF, as a heuristic device to analyze refugees' adversities and a basis to develop more appropriate interventions for them (e.g., Kira, 2001; Kira, 2010; Kira, Ashby, Lewandowski et al., 2013; Kira et al., 2006; Kira, Lewandowski, Chiodo, \& Ibrahim, 2014). Traumas classified in DBTF include attachment traumas, personal, role, and collective identity traumas, survival traumas, and interdependence traumas (for example, secondary and vicarious traumas). DBTF distinguishes between four types of trauma in terms of chronicity and severity: Type 1 a single episode (such as a car accident); Type II involves repeated similar traumatic episodes that have ceased, for example sexual abuse (see Terr, 1991); Type III is the ongoing and continuous systemic events, such as racism and gender discrimination (Kira, 2001; Kira, Ashby, Lewandowski et al., 2013); Type IV represents cumulative trauma (CT) that involves all stress and traumas across the lifetime. Cumulative effects of different trauma types may have a more serious impact and linear and non-linear dynamics (Kira et al., 2008; Kira, Fawzi, \& Fawzi, 2012; Kira, Omidy, \& Ashby, 2014) than single traumas (for a tables that summarizes this model see Kira, Fawzi, \& Fawzi, 2012; Kira, Ashby, Lewandowski et al., 2013).

The proposed typology of trauma-types reflects issues related to the inherent complexity of implications and consequences involved with exposures to traumatic stress. Severe cumulative adversities may cause a complex trauma (Ford \& Courtois, 2013) and different cumulative trauma profiles (Kira et al., 2008). Different trauma profiles may include unique comorbidities and profiles of symptoms, syndromes, and diagnostic categories (i.e., internalizing, externalizing, psychotic and other cumulative trauma disorders (CTD) in refugees) which are not 
captured by the PTSD model alone. CTDs are not new proposed diagnostic category/s. Different CTDs are empirically identified profiles of syndromes' comorbidities that may follow different profiles of cumulative trauma exposure, for example the CTD profile following refugee typical trauma profile which one of the focuses in current research (Kira et al., 2012). Such comorbidity profiles are explored empirically and observed clinically for the affected individuals and groups. These CTDs require distinct empirically defined assessment and trans-diagnostic treatment modalities and differentially responsive service systems. The complex trauma and the cumulative trauma disorder (CTD) models in refugees and torture survivors present an alternative trans-diagnostic model (Kira et al., 2008; Kira, 2010; Kira et al., 2012; Kira \& Tummala-Nara, 2014; McEvoy, Nathan, \& Norton, 2009; Moses \& Barlow, 2006).

\subsection{Cumulative Trauma and Its Effects on Multiply Traumatized (e.g., Torture Survivors Children)}

Epidemiological studies show, that refugees and their children (who are assumed to be more traumatized), compared to others have more psychotic disorders, and higher rates of comorbidities of depression, anxiety and PTSD (e.g., Bhugra, 2004; Fazel, Wheeler, \& Danesh, 2005; Selten, Cantor-Graae, \& Kahn, 2007). A great percentage of Iraqi refugees suffered from torture. Torture is not a single trauma. It is complex traumas that may include different trauma types, e.g., severe physical and sexual abuse and exclusion, that have inflicted over prolonged period or periods of time that target the person's personal and collective identity to self-surrender to capturer. The effects of torture go far beyond PTSD re-experiencing that they tend to suppress to more severe symptoms of dissociation and psychotic features (Kira, Ashby, Odenat, \& Lewandowski, 2013). Additionally, as Kira, 2004, noted that while adult refugees and torture survivors may be resilient, their children might be more negatively affected by, for example, the adult family member's torture experience. Such trans-generational secondary traumatization, as well as the negative effects of extreme stress on parenting skills and on increased domestic violence (e.g., Lambert, Engh, Hasbun, \& Holzer, 2012) contributes to their children's difficulties. Additionally current present adversities that include acculturative stress, limited employment opportunities, chronic discrimination's macro and micro aggressions (e.g., IRC, 2009), current adversities transmitted or communicated to them through direct contacts or media news about the war in their home land and the situation of their families and friends there (e.g., Kira et al., 2008), all are rarely addressed or factored in the current treatment models that focus on past single traumas.

Further, research suggests that parents' mental health disorders independent from shared genetics negatively affect the offspring's mental and physical health (Lewis, Rice, Harold, Collishaw, \& Thapar, 2011). Research on Iraqi refugee adolescents found an average of 9.17 traumas $(S D=3.88)$ (Kira et al., 2007, 2008). There is a need for a paradigm shift to a new trauma framework that guides potentially more effective interventions that address their unique adversities (Kira et al., 2013; Kira, 2013; Kira, Amer, \& Wroble, 2014, Kira \& Tummala-Narra, 2014; Kira \& Wroble, in press).

To summarize our argument, current conceptualizations of refugee children's adversities, their mental health status, and effective interventions to help them, though start emerging are still inadequate. The single event past trauma-based PTSD model, which is the current dominant approach, does not capture the experiences of refugee and torture survivor families who suffer repeated or chronic primary and secondary personal, interpersonal and collective intergroup and systemic present and past traumas (e.g. uprootedness, oppression, discrimination and torture) and their cumulative and proliferation dynamics (e.g., Kira et al., 2014). Present and ongoing chronic stressors such as ethnic discrimination, gender discrimination, community violence, and bullying, differ from past single traumas that most evidenced-based interventions are designed to address.

\subsection{Toward New Models of Intervention with Refugee Children}

The effectiveness and cross-cultural applicability of evidence-based interventions with refugee children (mostly focused on past and single traumas) has not been empirically established (e.g., Nickerson, Bryant, Silove, \& Steel, 2011). To address the gaps in current treatment models with multiply traumatized, Kira and others (Kira, 2013; Kira et al., 2013; Murray, Cohen, \& Mannarino, 2013; Kira \& Tummala-Narra, 2014) proposed a new intervention model to address both continuous and present traumas (Type I, II, and III), that are not typically addressed by current intervention models. The new Treatment Protocol focuses on ongoing and chronic adversities as part of a packaged sequential dynamic open system approach, proposed and initially tested here, and includes 
both present (e.g., Kira, 2013; Murray, Cohen, \& Mannarino, 2013) and past trauma-focused interventions (e.g., TF-CBT). It individualizes treatment over time via decision rules that specify whether, how, or when to change the intensity, type, or delivery of treatment at critical clinical decision points in individual and group therapy (.e.g., Lavoria \& Dawson, 2014). The intervention model provides the therapist the flexibility to address sequentially the client's unique current, continuous and emerging, as well as secondary and past traumas and their cumulative effects and proliferation dynamics according to the client's priorities and timeline of urgencies.

Current, continuous, and cumulative trauma-focused cognitive behavior therapy (CCC-TF-CBT), (Kira, 2013; Kira, Ashby, Omidy, \& Lewandowski, in press), a part of this packaged model, include four core components (behavioral, pre-cognitive, cognitive, and social), with eight intervention modes: Two behavioral interventions modes: 1) prioritizing safety, and addressing current and ongoing threats and dangers: distinguishing real danger from exaggerated, down played (avoided) and the real challenges (e.g, Najavits, 2002; Murray, Cohen, \& Mannarino, 2013); 2) practicing basic skills training to deal with real threats and dangers (e.g. problem solving, assertiveness training, mindfulness training, anger management, personal and group-based emotion regulation, and enhancing participation and engagement) (e.g., Lyman et al., 2014; Liu, Huang, \& Wang, 2014); two pre-cognitive intervention modes; 3) stimulating "will to live and survive and related meaningful effective coping strategies (e.g., Bonanno \& Mancini, 2008, Kira, Alawneh, Aboumediene, Lewandowski, \& Laddis, 2014); and 4) identity work, identities reconfiguration, and identity development that may include: redefinition of identities (e.g., gender sexual, racial, religious, national, species in addition to; personal and collective self-esteem and self-efficacy) (e.g., Scheepers, Spears, Manstead, \& Doosje, 2009; Gaertner \& Dovidio, 2005) and three cognitive intervention modes; 5) psycho-education of continuous traumatic stress and cumulative and proliferation and stress generation dynamics (e.g., Kira et al., 2013; Kira et al., 2014); 6) inoculation against stress proliferation and accumulation dynamics and training to identify and disrupt such existing dynamics; and 7) narration and writing intervention and one social intervention modes (e.g., Travagina, Margolaa, \& Revensonb, 2015); 8) reconnection, advocacy and social Justice using Scientist-Practitioner-Advocate (SPA) model (Mallinckrodt, Miles, \& Levy, 2014). Diagram 1 visualizes this model.

The proposed treatment model will be utilized as part of multi-systemic, multi-modal, multi-component program that was impeded in a summer day treatment of after school program. Systemic traumas (e.g., Kira et al., 2014) may be better addressed through systemic and multi-systemic, multi-component, multi-modal wide range ecological approach with different treatment arms that include the proposed interventions. Further, case management and the social work approach that give more attention to the active intervention with the social context might be effective within multisystem treatment than individual and group interventions alone (e.g., Bruns, Pullmann, Sather, Brinson, \& Ramey, 2015). Successful work with children who live with their families and attend schools is more easily accomplished when families and schools are allied with the therapist and included in the multi-systemic treatment. Case managers can help refugee families collaborate more successfully with a child's school, help school personnel understand the adversities that refugee children have endured (Rosenberg, Gonzalez \& Rosenberg, 2005), and help develop systemic and milieu interventions within the family

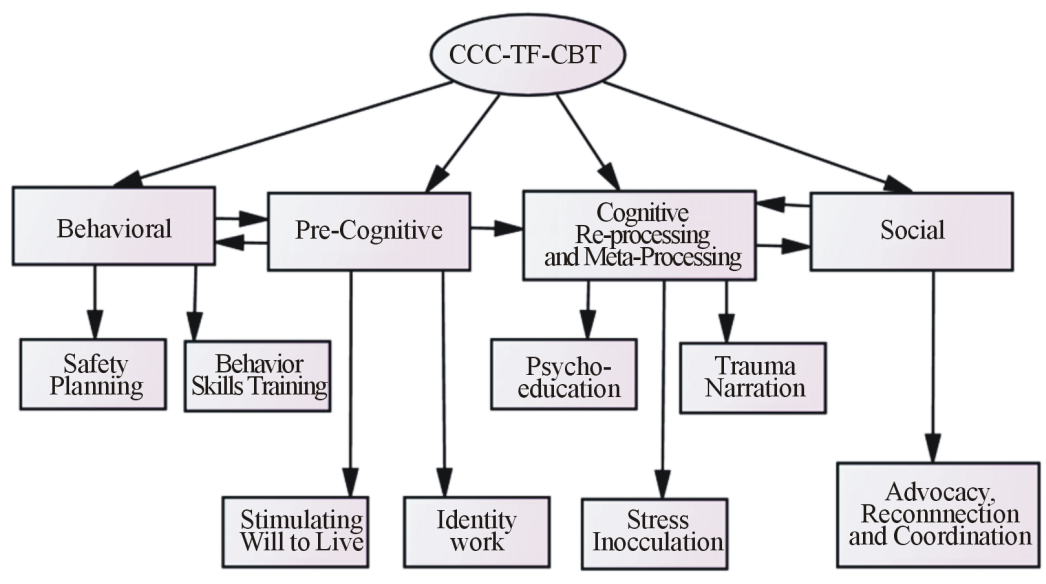

Diagram 1. The components and intervention modes for current, continuous, and cumulative trauma-focused cognitive behavior therapy (CCC-TF-CBT). 
and classroom consistent with the therapy room.

Development and piloting complex interventions (interventions that contain several interacting components) require using the best available evidence and appropriate theory and recognition that such interventions may work best if they are based on previous evidence-based interventions and tailored to clients' contexts rather than completely standardized or rigidly manualized, using the insights provided by the theory of complex adaptive systems (Campbell et al., 2007). Flexible application of a treatment protocols found to produce outcomes equivalent to those obtained in strict adherence to such protocols (e.g., Levitt, Malta, Martin, Davis, \& Cloitre, 2007). Current work is a pilot study to determine if the proposed, newly developed, intensive multi-systemic, multi-modal and multi-component family/school/community-based ecological treatment "summer day treatment and after school (SDTAS model" that addresses past, present and ongoing traumas in refugee children (from open system dynamic perspective) can be implemented successfully (see Table 2 for detailed description of the program and its components), and provide initial proof of its potential consequential effectiveness in refugee children. We conducted a Prospective One year Empirical Study to evaluate the program. This should provide support for the feasibility of conducting future larger scale studies with more rigorous experimental design with refugee children.

It was hypothesized that the program utilizing the SDTAS approach, that address both past and present ongoing traumas as well as chronic and prolonged stressors and their accumulation and proliferation dynamics, would be associated with statistically and clinically significant reduction in PTSD, cumulative trauma disorders (comorbid syndromes), depression, and anxiety symptoms and increased functioning in youth who suffered from cumulative refugee trauma and who were unresponsive to treatment as usual (using psychiatric and singletrauma focused cognitive behavior interventions).

\section{Method}

\subsection{Procedures and Setting}

The program was administered from June 2004 to June 2005 as both a summer day treatment and after-school program and was made possible by a grant from the Office of Refugee and Resettlement to help Iraqi children from torture survivors' families who were unresponsive or treatment resistant. The setting was a large children's mental health clinic (affiliated with a community organization) in operation in Michigan for more than 10 years. The clinic treated over 350 children a year, mostly refugees of Arab and Middle Eastern descent. Approval of the study was obtained from the institution's IRB. Active informed consents of parents and written accents of children were obtained. The SDTAS program was administered (in the English language) five days a week after school (4 - $7 \mathrm{pm}$ ) and one weekend day (for six months), and for five days a week during the summer months (from $9 \mathrm{am}-4 \mathrm{pm}$ ). The treatment was administered by a team of 3 licensed bi-lingual or bi-cultural therapists who were either master level psychologists or social workers with an eclectic or cognitive-behavioral orientation. The team included 3 certified case managers, and a Board certified psychiatrist. The team received special training on the program during a retreat. Audio/video materials were used in training. A doctoral-level psychologist led a weekly two-hour group supervision session to assess and follow up on each case, to make sure that clinicians were sticking to the treatment protocol, and to provide more training for the next planned weekly sessions. Furthermore, every therapist was provided bi-weekly individual supervision. Additional time was taken for home-based intervention and follow-up with the school teachers, counselors, probation officers, and community ethnic organizations. The activities occurred indoors, outdoors and at the participant's home depending on activity type. Transportation and lunch were provided with no cost to participants. Attendance and participation in the program (which was recorded daily) and their adherence to treatment was high (95\%). Failure to attend the program for three consecutive days without an excused absence was ground for dismissal but did not occur.

The activities of the program took place in community centers with cooperation with schools. Child psychiatrists previously made the psychiatric diagnoses after a thorough diagnostic interview using DSM-IV criteria. All patients were prescribed medication by psychiatrists' choice, and all were on an either antidepressant (SSRIs, tricyclic) (70\%), anti-psychotic (40\%), mood stabilizer (10\%), and/or an ADHD stimulant (30\%) or a combination of those (80\%), for at least six months before and throughout the entire treatment period. Individual cognitive behavior therapy, as well as parenting training accompanied the medication for the last six month, before the program, and had little or no effects on their symptoms. Participants were assessed at three time points: intake (pre-treatment), five months, and at ten months (times 1, 2, and 3). Time 3 testing was conducted at the end of the program. Mental health professionals (licensed psychologists or social workers) outside of the program 
who were blinded to the study goals conducted assessments through face-to-face interviews.

Unique strategies were used to engage youth and families. While there was no direct financial incentives, indirect incentives such as field trips, the therapeutic computer games, the point system that allows those at high points to be hired and paid as assistant group leaders, free transportation, lunches and snacks, entertainment that included a magic show, and feeling connected to the group and strong support developed through group and teams dynamics, as well as the bi-cultural, bi-lingual treatment team that were culturally competent and consistent with their cultural heritage, all were powerful strategies to engage Iraqi youth and their families, and ensured high retention rate.

\subsection{Participants}

Due to the goals of the trial and the grant stipulations to address only the non-responding cases from Iraqi refugee torture survivors' families, referrals were solicited primarily from the clinic psychiatrists and therapists who identified the most difficult to treat cases with poor response rates to treatment as usual and who belong to torture survivors 'refugees' families. Many of the referred participants had persistent complaints from their school teachers and administration, and some from their probation officers, as well as from parents concerning their behavior, performance and poor emotional regulation. Thirty-two participants, who meet the inclusion/exclusion criteria, were accepted for treatment. Participants were children of Iraqi refugee torture survivors aged 11 - 14 years. They were diagnosed with at least two comorbid diagnoses (PTSD diagnosis was present as primary or secondary diagnosis for all participants), exhibited poor functioning (GAF score $\leq 50$ ), and received medication and therapy for at least six months prior to the intervention with little or no response (they continue to use the same medications during the program). Using cumulative trauma scale (CTS) (Kira et al., 2008) at intake, participants were found to be multiply traumatized (mean types of traumas occurrence [SD] is 10.35 (3.34), and 15.12 [5.11] for trauma frequency. All reported between 8 and 26 trauma types. Their highest exposure was to secondary traumas (e.g. parents torture) $(\mathrm{M}=2.86, \mathrm{SD}=1.74)$, followed by survival traumas $(\mathrm{M}=0.60, \mathrm{SD}=$ $0.78)$, personal identity traumas $(\mathrm{M}=0.52, \mathrm{SD}=0.61)$, collective identity trauma $(\mathrm{M}=0.50, \mathrm{SD}=0.68)$, abandonment or separation from parents $(\mathrm{M}=0.13, \mathrm{SD}=0.38)$. The discrimination, backlash, and bullying after September 11, 2001 attacks was notable for Iraqi adolescents, while not measured in this groups, another studies of a comparative group documented its severity and its negative effects on their mental health and cognitive functioning (Kira, Lewandowski, Chiodo, \& Ibrahim, 2014; Kira, Lewandowski, Ashby et al., 2014). Participants with a mental retardation diagnosis were excluded from the study. Five children dropped out of the program due to relocation out of the study area. Twenty seven participants remained in the program. All participants were first generation refugees, and English was the second language for them (first language was Arabic), however, all have adequate grasp of English and the program was conducted primarily in English. Table 1 describes their general demographic and clinical characteristics.

\subsection{Highlights of the Treatment Model: Summer Day Treatment and After School (SDTAS)}

The SDTAS treatment model is multi-systemic, multi-component and multi-modal. The program engages in community, family, group settings and other systems in which the child is involved and was conducted by a community mental health organization. SDTAS is multi-modal in utilizing an individualized, person-, family-, school-, and community-centered holistic approach. It is multi-component in that it includes several interventions in addition to therapy such as case management, legal, medical, school, and community interventions. In addition to manualized and pre-planned interventions, open system interaction based-interventions were adopted to address chronic, ongoing, as well as emergent behaviors and events in clients' life. Group therapy had stable and structured integrating different and large number of components to be delivered manualized, but through flexibly open system approach according to the group needs and interactions. Individual therapy was individualized and person centered that has stable components to be delivered flexibly according to the emergent events, needs and behaviors of the client. Flexibility entails that the same components can be delivered with different orders according to the clients and situational needs and to the best clinical judgment of the treatment team. Some components were not included in the initial plan, and the treatment team, during case discussions, decided to add them to address certain observed or emergent needs, behaviors or events. Flexibly integrated stable components generally characterize the fidelity status of the intervention. 
Table 1. The general demographic and clinical characteristics of the participants.

\begin{tabular}{|c|c|}
\hline Demographic and clinical characteristics & $\%, \mathrm{M}=$ Mean, $\mathrm{SD}=$ Standard Deviation \\
\hline Gender & 51.9\% Females (14), 48.1\% Males (13) \\
\hline Age & $11-14$, Mean $=11.19, \mathrm{SD}=0.62$ \\
\hline Grade level & $5-8$ grades $70 \%$ grades $5-6,30 \%$ grades $7-8$ \\
\hline Parenting status & $\begin{array}{l}24 \text { (89\%) have both parents, } 1 \text { live with his single mother who is a torture survivor, } 1 \\
\text { live with a single father, and } 1 \text { lives with uncle who is a torture survivor. }\end{array}$ \\
\hline Family income & Range of $\$ 10,000$ to $30,000 \$$ a year, Mean $=\$ 20444.44, \mathrm{SD}=\$ 5056.10$ \\
\hline Family size & Range between $3-9$, Mean $=5.56, \mathrm{SD}=1.5$ \\
\hline Ethnicity and Status & $100 \%$ first generation Iraqi refugees with 2 - 5 years residency in the US \\
\hline $\begin{array}{l}\text { Primary Diagnosis PTSD and Major Depression } \\
\text { with Psychotic features (comorbid) }\end{array}$ & $70 \%(19)$ \\
\hline $\begin{array}{l}\text { Primary Diagnosis ADHD combined type with } \\
\text { Bipolar and PTSD comorbidity }\end{array}$ & $30 \%(8)$ \\
\hline GAF Scores at Intake & $\mathrm{M}=41.78, \mathrm{SD}=5.61,($ range $32-50)$ \\
\hline History of Torture in the family & $\begin{array}{l}\text { 82\% (22) has at least one parent who is a torture survivor } 18 \% \text { (5) with close relative } \\
\text { (e.g., brother) who survived torture }\end{array}$ \\
\hline
\end{tabular}

Table 2 describes the highlights of structural components, modalities and systems involved in (SDTAS), and their sources in previous evidence-based studies.

\subsection{Measures}

The following measures were selected to be used in the current study, as they have previously demonstrated good reliability and validity for use with refugees adolescents (e.g. Kira, Smith, Lewandowski, \& Templin, 2010; Kira et al., 2008; Kira et al., 2007; Kira et al., 2006). We used PTSD (CAPS-2) adult version as it was already validated for use with refugee adolescents, while the child version weren't. Further, the CTD measure was specifically developed to assess prevalent traumas spectrum disorders in refugees' adults and adolescents in other studies (Kira et al., 2012); CES-D (depression) and DASS measures were used with adults and adolescents in previous studies. We used the English versions in interview format. The measures included:

Clinician Administered PTSD Scale (CAPS-2): widely used to assess PTSD. It is a structured, clinical interview assessing 17 symptoms. CAPS has demonstrated high reliability ranging from 0.92 - 0.99 and was shown to have good convergent and discriminant validity (Weathers, Keane, \& Davidson, 2001). This study adopted the frequency sub-scale of CAPS-2 that is widely used in psychiatric literature. It demonstrated high reliability (alpha $=0.92)$ in the present study.

Cumulative trauma disorder measure (CTD) (Kira et al., 2012). This 15-item index measure developed in previous studies with Iraqi refugees' adults and adolescents to assess symptoms associated with cumulative trauma and/or complex PTSD in refugee children and adults. It demonstrated high reliability (ranging from 0.850 and 0.987 ), and construct, convergent, divergent and predictive validity. The measure assesses 13 symptoms: depression, anxiety, somatization, dissociation, auditory and visual hallucinations, avoidance of being with people, paranoid ideations, concentration and memory deficits, loss of self-control, feeling too harsh with family and people in general, feeling suicidal, and thoughts of hurting one's self. Exploratory and confirmatory factor analyses found that the measure has four factors and sub-scales: loss of control and executive function deficits, suicidality, psychosis/dissociation comorbidity, and depression/anxiety/somatization comorbidity. The measure displayed adequate alpha reliability (0.91) in the current data.

The Center for Epidemiologic Studies Depression Measure (CES-D; Radloff, 1991). The CES-D is a 20-item scale designed to measure depression. Each item is assessed on a four-point scale and reflects the frequency that each symptom is experienced ( $0=$ none of the time, $3=$ all of the time). Adequate reliability and validity have been reported for the CES-D among various adults and adolescent groups. A cutoff score of $\geq 16$ is commonly used for the CES-D to indicate a need for further assessment of the presence of Major Depressive Disorder (Radloff, 1991). Chronbach's alpha for the measure in this study was calculated at 0.91. 
Table 2. The structural components, modalities and systems involved in sdtas and their sources in previous evidence-based studies.

$$
\text { Intervention Component Source or Modality }
$$

Comprehensive Trauma Assessment, Development-based trauma framework Comprehensive psycho-social assessment-Case conceptualization (DBTF) (e.g., Kira, 2001; Kira et al., 2013) comprehensive psychosocial assessment

Psychiatric evaluation and medication prescriptions

Standard mental status exams

Individual Therapy (12 - 14 hourly sessions during the program with its two components $)(\mathrm{M}=13.0, \mathrm{SD}=$ 1.2 per client)

Daily groups (4 times a week) (36, hour and half sessions during the program with its two components) ( $\mathrm{M}=34.0, \mathrm{SD}=1.8$, per client $)$

(e.g., Ruf et al., 2010); (Cohen, Mannarino, Deblinger, 2006)

Kira's model for intervention with continuous traumatic stress (Kira, 2013; Kira, Ashby,

Omidy, \& Lewandowski, in press; Kira et al. 2013). Recovery Group Education and Therapy TARGET (Ford \& Russo, 2006), Ford \& Courtois, 2013; Courtois \& Ford, 2013

Education and homework assistance, Huang \& Cho, 2009; Study groups

Springer \& Diffily, 2012

Computer-assisted therapy An hour

session a week (20 sessions) $(\mathrm{M}=$ Grist \& Cavanagh, 2013 18.1 , SD = 1.6, per client) CATTI (Chapman, Morabito, Ladakakos, Schreier, \& Knudson, 2001)

Art Therapy An hour session a week (20 sessions during the program with its two components))

Recreational and activity Therapies (8 Field trips during the program McGhee, Groff, \& Russoniello, 2005 with its two components) )

Milieu Therapy (ongoing through the program with daily behavior charts and weekly feedback. Three have Gunderson, J. G. (1978) been hired through the points program as assistant group leaders) Unplanned, on the spot, open system Unique in this program
interventions

Re-rooting and connecting (9 Monthly planned visits)

Unique in this program

Highlights

Comprehensive trauma screening using DBTF measuring cumulative trauma including secondary exposure.

Standard psychiatric evaluations by psychiatrist and therapist upon intake and on times 1 and 2. Medication prescriptions by psychiatrists

Bi-weekly and as needed to address emergent issues: Narrative exposure therapy; Trauma Focused-Cognitive Behavioral Therapy (TF-CBT) (exposure component not included)-addressing emergent behaviors and issues.

Psychoeducation, identity work, and violence prevention, anger management and personal and group-based emotion regulation. Behavioral skills building (e.g., problem solving, assertiveness-social skills, mindfulness)-Identity work-Present trauma focused-Discrimination and bullying-focused intervention-Gender discrimination-Past-trauma focused interventions-Narration and writing assignment about personal experience.

Computer literacy to improve digital and cyber skills and feelings of cyber efficacy, library usage, Homework assistance, Study groups for different projects

Therapeutic games, cognitive and attention training

Group drawings and art projects

Field trips to museums and other places of interest to increase group cohesiveness through positive group interactions and joint learning experiences.

Reward-based individualized behavior management tailored to each client's needs. Level and point systems. Those who reached level one were provided with the opportunity to work as assistant group leaders and receive financial compensation and leadership training

Targeting specific behaviors that may emerge during the course of daily interactions, (as well as emergent events in client's life). This element is critical as it addresses behavioral problems and emotional issues immediately upon emerging, as well as immediate reinforcement for progress. Staff is trained for these unplanned events.

Connect with ethnic and cultural clubs and ethnic and community organizations through visits, membership and internet.

Home-based: Parent Training (hour Brookman-Frazee, Stahmer, Baker-Ericzen, \&Home-based parental training-Addressing gender discrimination and half monthly session) 8 sessions Tsai, 2006 and effects

Home-based family Therapy (12 hourly sessions during the program with its two components)

Advocacy and follow up and collaboration with school and other community organizations School-based interventions (Average 25 contacts per client)
Figley's (1988) five-phase treatment of PTSD in families

Wraparound system of care (e.g., Cicchetti \& Cohen, 1995). TST (Saxe et al., 2007), Multi-Tier Mental Health Program for Refugee Youth (Ellis et al., 2013), Trauma Systems Therapy (Saxe, Ellis, \& Kaplow, 2007). Social justice advocacy (Goodman \& Gorski, 2015)
Bi-weekly structural family therapy intervention for the first three months of the program followed by monthly follow-up home visits for an additional three months.

Follow up with teachers and counselors in schools, and probation officers (bi-weekly and as needed)-Consult and coordinate with teachers and counselors on individualized behavioral plans in school and the program (bi-weekly and as needed). Conduct conferences with teachers and all involved on the issues of children of torture survivors, to increase awareness understanding and empathetic concerns. 
Depression Anxiety Stress Scales-Anxiety DASS-A: Anxiety Sub-scale (Lovibond and Lovibond, 1995). The DASS consists of three sub-scales to measure depression, anxiety, and stress. We used only anxiety sub-scale as it has been previously utilized with reliable results in this population. The anxiety sub-scale (14 items) of the DASS, has been increasingly utilized in clinical and research settings with adults and adolescents. Different studies suggest that anxiety sub-scale possesses adequate convergent validity, and reliability (Lovibond \& Lovibond, 1995). Alpha was calculated at 0.89 in the present study.

Global Assessment of Functioning $(G A F)$ was assessed by clinic psychiatrists at baseline, times 2 and 3.

\subsection{Analysis}

\subsubsection{Intention to Treat Analyses}

The study was an exploratory in nature to evaluate the feasibility of a larger, controlled and more rigorous study. There was no significant difference in the initial GAF scores between participants who dropped out and those who did not. The dropout rate was relatively low (16\%) which makes the differences between the analytical methods less significant. The dropouts occurred in the first few month of the academic school year and were not assessed at time two or three. In addition, the reason for dropout was not related to the study or therapy protocol (moving out of area). The prognosis did not differ in patients who dropped out. Accordingly, the drops out participants were excluded from the statistical analysis and focused on completers.

\subsubsection{Statistical Analysis}

IBM-SPSS 22 statistical package was used to perform the analysis. Prior to all univariate and multivariate analyses, data were screened for outliers and all relevant assumptions were satisfied (Tabachnick \& Fidell, 2013). Reliability coefficients were then calculated all for measures (PTSD. CTD, Anxiety and depression). Additionally GLM Repeated Measures ANOVA (e.g., Weinfurt, 2000) was used to evaluate the changes in each dependent variable (PTSD, CTD, depression and anxiety, and GAF) across the three time points (time 1 upon intake, and times 2 and 3 every 4 months after). An ANOVA with repeated measures is used to compare three or more group means where the participants are the same in each group.

\section{Results}

Repeated measures ANOVA determined that mean PTSD, Depression, CTD, and GAF differed statistically significantly between the three time points. Post hoc tests using the Bonferroni correction revealed that the program elicited a significantly high reduction in the measured symptoms, and significantly increased GAF, from time 1 (intake) to time 3 (close to the end of the program). There were significant difference between condition means, while the PTSD(CAPS-2), CTD, depression (CES-D), and anxiety (DASS-A) total scores were clinically high at baseline, they dropped significantly at time two and continued to significantly drop to a non-clinical range at time three. Depression scores in particular decreased significantly to a non-clinical range at time two and maintained these treatment gains at time three. GAF scores were significantly increased as well indicating increased in the clients overall functioning. There was a significant effect sizes of the program on depression reduction, (Wilks' Lambda $=0.07, \mathrm{~F}(2,25)=165.10, p=0.000$, Partial Eta Squared $=0.93$ ), on reduction in PTSD (Wilks' Lambda $=0.16$, F $(2,25)=67.87, p=0.000$, Partial Eta Squared $=0.84)$, on anxiety reduction (Wilks' Lambda $=0.07, \mathrm{~F}(2,25)=160.48, p=0.000$, Partial Eta Squared $=0.93$ ), on CTD symptoms reduction (Wilks' Lambda $=0.15, \mathrm{~F}(2,25)=73.54, p=0.000$, Partial Eta Squared $=0.86)$; and on increased GAF scores (Wilks' Lambda $=0.08, \mathrm{~F}(2,25)=138.38, p=0.000$, Partial Eta Squared $=0.92)$. The effect sizes of the change were notably too high to be due to chance or error. Table 3 provides Parameters Estimates and estimated margin means of the change in each variable over the time of the program, their confidence intervals, significance and effects size for times one, two, and three. Table 4 provides pairwise comparisons between the three time points and their confidence intervals and their effect sizes using Bonferroni to adjust for multiple comparisons.

Additionally, 89\% scored at or above the 16 cut off score for clinical depression (on CES-D) at time one. At time 3, only $4 \%$ remained on or above the 16 cut off score. There is only one case in which depression rather increased 1 point (non-significant) at time 3; however, PTSD decreased 22 points at time 3 in the same case. In regards to GAF, $14.8 \%$ scored on the 50 score (the median level) at time 1 , with $66.7 \%$ scoring above 50 at time three. Similar clinical results were found for the other clinical scales, indicating good clinical and practical significance of the statistically significant results. 
Table 3. Means and standard deviations (M(SD)), Parameters estimates, their significance, 95\% confidence intervals and effect sizes (partial eta squares) for depression, PTSD, anxiety, CTD, and GAF at times one, two, and three.

\begin{tabular}{|c|c|c|c|c|c|c|c|c|}
\hline \multirow[b]{2}{*}{ Variables } & \multirow[b]{2}{*}{$\mathrm{M}(\mathrm{SD})$} & \multirow[b]{2}{*}{ B } & \multirow[b]{2}{*}{ SE } & \multirow[b]{2}{*}{$\mathrm{t}$} & \multirow[b]{2}{*}{ Sig. } & \multicolumn{2}{|c|}{ 95\% Confidence Intervals } & \multirow{2}{*}{$\begin{array}{l}\text { Partial Eta } \\
\text { Squared }\end{array}$} \\
\hline & & & & & & $\begin{array}{l}\text { Lower } \\
\text { Bound }\end{array}$ & $\begin{array}{l}\text { Upper } \\
\text { Bound }\end{array}$ & \\
\hline Dep. Time1 & $19.0(3.64)$ & 19.00 & 0.70 & 270.14 & 0.000 & 17.56 & 20.44 & 0.966 \\
\hline Dep. Time2 & $6.5(2.64)$ & 6.46 & 0.51 & 12.72 & 0.000 & 5.41 & 7.50 & 0.862 \\
\hline Dep. Time3 & $7.5(2.98)$ & 7.50 & 0.57 & 13.09 & 0.000 & 6.32 & 8.68 & 0.868 \\
\hline E. M. Means & 10.99 & & 0.41 & & & 10.15 & 11.82 & \\
\hline PTSD. Time1 & $27.0(9.64)$ & 27.00 & 1.85 & 14.56 & 0.000 & 23.19 & 30.81 & 0.891 \\
\hline PTSD. Time2 & $9.0(6.55)$ & 9.00 & 1.26 & 7.14 & 0.000 & 6.41 & 11.59 & 0.662 \\
\hline PTSD. Time3 & $5.1(3.89)$ & 5.10 & 0.75 & 6.82 & 0.000 & 3.56 & 6.64 & 0.641 \\
\hline E. M. Means & 13.70 & & 0.96 & & & 11.74 & 15.66 & \\
\hline Anx. Time1 & $25.5(7.01)$ & 25.46 & 1.350 & 18.862 & 0.000 & 22.69 & 28.24 & 0.932 \\
\hline Anx. Time2 & 3.7 (2.39) & 3.73 & 0.459 & 8.113 & 0.000 & 2.78 & 4.67 & 0.717 \\
\hline Anx. Time3 & $0.70(0.40)$ & 0.70 & 0.08 & 9.16 & 0.000 & 0.54 & 0.86 & 0.763 \\
\hline E. M. Means & 9.96 & & 0.49 & & & 8.95 & 10.98 & \\
\hline CTD Time1 & 10.7 (4.43) & 10.74 & 0.85 & 12.61 & 0.000 & 8.99 & 12.49 & 0.859 \\
\hline CTD Time2 & $4.6(2.39)$ & 4.64 & 0.46 & 10.08 & 0.000 & 3.69 & 5.58 & 0.796 \\
\hline CTD Time3 & $1.9(1.13)$ & 1.90 & 0.22 & 8.78 & 0.000 & 1.46 & 2.35 & 0.748 \\
\hline E. M. Means & 5.76 & & 0.36 & & & 5.01 & 6.51 & \\
\hline GAF Time 1 & $41.8(5.61)$ & 41.78 & 1.08 & 38.73 & 0.000 & 39.56 & 44.00 & 0.98 \\
\hline GAF Time 2 & $49.6(5.33)$ & 49.59 & 1.03 & 48.35 & 0.000 & 47.48 & 51.70 & 0.99 \\
\hline GAF Time 3 & $54.3(4.43)$ & 54.26 & 0.85 & 63.71 & 0.000 & 52.51 & 56.01 & 0.99 \\
\hline E. M. Means & 48.54 & & 0.92 & & & 46.66 & 50.42 & \\
\hline
\end{tabular}

Note: Dep. = Depression, Anx. = Anxiety, E. M. Means = Estimated Marginal Means.

Table 4. Pairwise comparisons: mean differences and $p$ values for significance of differences between times 1, 2 and 3, their confidence intervals and their effect size (partial eta squared) in PTSD, CTD, anxiety, depression and GAF.

\begin{tabular}{|c|c|c|c|c|c|c|}
\hline \multicolumn{2}{|c|}{ Mean differences, $p$, and confidence intervals } & PTSD & CTD & Anxiety & Depression & GAF \\
\hline \multicolumn{2}{|c|}{ Mean Difference between Time 1 and time 2} & 18.00 & 6.07 & 21.78 & 12.45 & -7.82 \\
\hline \multicolumn{2}{|c|}{ Std. Error } & 1.81 & 0.94 & 1.36 & 1.81 & 0.55 \\
\hline \multicolumn{2}{|c|}{$p$} & $<0.001$ & $<0.001$ & $<0.001$ & $<0.001$ & $<0.001$ \\
\hline \multirow{2}{*}{$\begin{array}{l}\text { 95\% Confidence Interval for } \\
\text { Difference }\end{array}$} & Lower Bound & 13.46 & 3.70 & 18.27 & 10.74 & -8.93 \\
\hline & Upper Bound & 22.54 & 8.50 & 25.20 & 14.35 & -6.69 \\
\hline \multicolumn{2}{|c|}{ Mean Difference between Time 1 and time 3} & 21.86 & 8.79 & 24.80 & 11.50 & -12.48 \\
\hline \multicolumn{2}{|c|}{ Std. Error } & 1.91 & 0.79 & 1.38 & 1.91 & 0.78 \\
\hline \multicolumn{2}{|c|}{$p$} & $<0.001$ & $<0.0001$ & $<0.001$ & $<0.001$ & $<0.001$ \\
\hline \multirow{2}{*}{$\begin{array}{l}\text { 95\% Confidence Interval for } \\
\text { Difference }\end{array}$} & Lower Bound & 17.07 & 6.76 & 21.26 & 9.38 & -14.08 \\
\hline & Upper Bound & 26.73 & 10.92 & 28.27 & 13.63 & -10.88 \\
\hline \multicolumn{2}{|c|}{ Mean Difference between Time 2 and time 3} & 3.86 & 2.72 & 3.02 & -1.1 & -4.67 \\
\hline \multicolumn{2}{|c|}{ Std. Error } & 1.37 & 0.47 & 0.49 & 0.37 & 0.62 \\
\hline \multicolumn{2}{|c|}{$p$} & 0.01 & 0.001 & 0.001 & 0.38 & $<0.001$ \\
\hline \multirow{2}{*}{$\begin{array}{l}\text { 95\% Confidence Interval for } \\
\text { Difference }\end{array}$} & Lower Bound & 0.41 & 1.54 & 1.80 & -2.97 & -5.94 \\
\hline & Upper Bound & 7.39 & 3.94 & 4.25 & 0.88 & -3.40 \\
\hline \multicolumn{2}{|c|}{ Partial Eta Squared (Effect size) } & 0.844 & 0.855 & 0.928 & 0.930 & 0.917 \\
\hline
\end{tabular}


Further, we compared gender differences in symptom improvement. Females were generally higher in symptoms than males, except for anxiety, at base line, but the differences were not significant between genders at time 3. Figures 1-4 illustrate the progress for males and females over the three time periods on each measure (PTSD, CTD, depression and anxiety).

Therefore, we can conclude that the MMMM Ecological Interactive Open Systems interventions elicit a statistically and clinically significant reduction in symptoms of depression, anxiety, CTD and PTSD, and significant increase in functioning (GAF). We can conclude that the traditional differences between males and females, with females more symptomatic than males, significantly reduced or disappeared.

Case example: Fatima is an 11-year-old female and Iraqi refugee. Her mother, a single parent, takes care of her six children with little support. Fatima was presented to the clinic with complaints of bedwetting. A teacher described her as appearing somewhat withdrawn and depressed, having low self-esteem and difficulties coping with various residential moves the family has made. There was concern about serious academic deficits and delayed second language acquisition. The teacher reported that at time of admission, Fatima continually asked for help with schoolwork, failed to finish tasks she started, had difficulty concentrating, daydreamed frequently, had difficulty following directions, preferred to be alone rather than with others, was under active and slow moving,

\section{Estimated Marginal Means of PTSD}

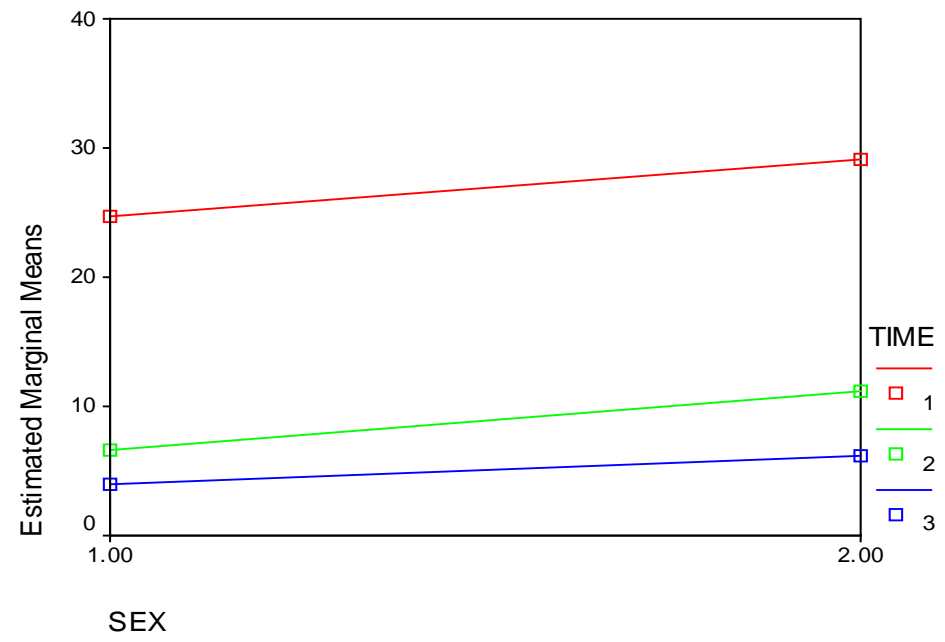

Figure 1. The change in PTSD scores over time by Gender $(1.00=$ males, 2.00 = females).

\section{Estimated Marginal Means of CTD}

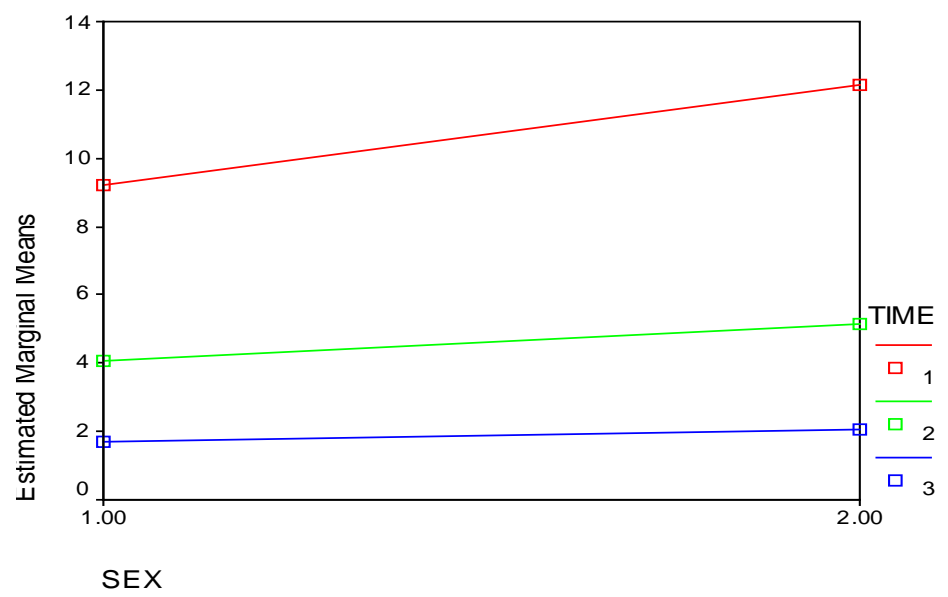

Figure 2 . The change in CTD scores over time by Gender $(1.00=$ males, 2.00 females $)$. 

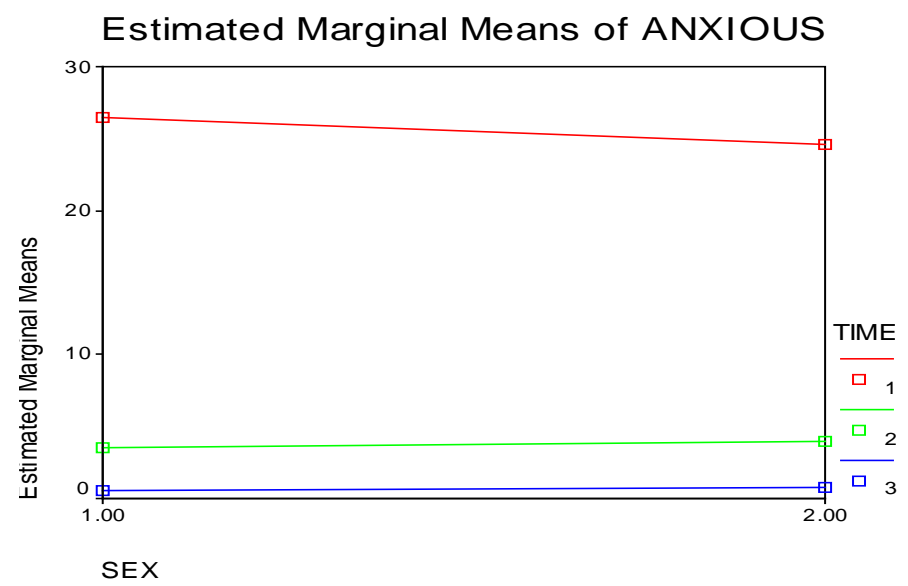

Figure 3 . The change in Anxiety scores over time by Gender (1.00 = males, $2.00=$ females $)$.

Estimated Marginal Means of DEP

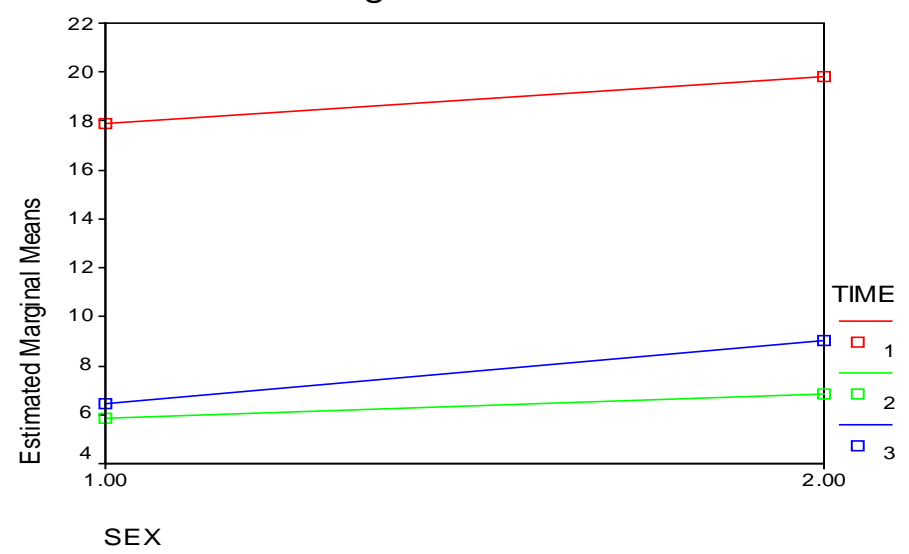

Figure 4 . The change in depression scores over time by Gender $(1.00=$ males, 2.00 = females).

worried frequently, spent a significant portion of time in the restroom, and required significant positive reinforcement. School records indicated that the client had repeated the third grade twice. Previous attempts tominimize bed-wetting by restricting fluids before bed and waking Fatima at night did not work. She was administered a course of Tofranil by the family physician with little response. A trauma screening found that her father participated in the Iran-Iraqi war and was jailed and tortured. Her parents divorced three years ago due to infidelity by the father and his domestic violence perpetuation that involved both mother and child. Fatima experienced gender discrimination as her brothers were favored by the family, which made her feel relatively demeaned. In school she was victimized by bullying, as well as by discrimination for her ethnic and religious background (i.e. Arab Iraqi refugee and Muslim). The family relocated frequently, which necessitated that the client change schools on numerous occasions. The results of intellectual testing determined that she was in the borderline range with a full-scale IQ of 76. Symptoms of PTSD were evident as Fatima was easily frightened by change, had sleep disturbances, and traumatic dreams. Her diagnoses were as follows: Axis 1: PTSD, ADHD inattentive type, and functional enuresis; AXIS 2: R/O borderline intellectual functioning; AXIS 4: stressors include father's mental illness, parental conflicts, acculturation, financial stress, and housing problems. Her GAF score was 48.

Fatima participated in the summer day treatment and after school program. Restoring the child's sense of safety and self-worth was the first and most important step in her healing. In addition, the program provided the opportunity for her to experience belonging to the community and to exercise positive interactions with peers and adults. Fatima stated that, "the happiest time was when we were in a safe place." The interdisciplinary bi- 
lingual team of therapist, social worker, case manager and psychiatrist applied the ecological multi-systemic, multi-modal, multi-component interventions and utilized Kira's model for continuous trauma focused interventions (Kira, 2013: p. 14), (Kira et al., 2013: p. 13), and trauma focused, present centered TARGET model (Ford \& Russo, 2006: p. 48). Interventions included medication (bio-physiological level), home visits to work directly with her in her natural environment, as well as with the family system, connecting her with her peers in the daily groups and in the community (to reestablish meaningful connections, and facilitate healthy acculturation that reinforce both her emerging bi-cultural identity and address uprootedness). Home visits, according to her home-based therapist, helped to reframe and form intervention in a flexible way that addressed secondary and direct past and ongoing traumas in her natural and family environment. Individual treatment focused on psycho-education on the cumulative dynamics of past and ongoing traumas (meaning making) that she survived and are surviving. Bi-cultural identity work, and confronting ongoing threats and dangers, helped her developing and accepting her bi-cultural new identity. Skills training were important to increase feelings of mastery and self-efficacy, and to strengthen her coping response by empowering her as strong survivor who continued to resist gender and other forms of discrimination. The interventions helped to move the client towards better functioning in home and school. She developed new insights and positive meanings from her experience, increased her distress tolerance, personal and group-based emotional regulation and mindfulness skills, and focused more on the present, and looked forward to the future. The availability and utilization of a bi-lingual team was important in facilitating effective culturally competent, trusted interventions that minimized negative transference and counter-transference.

Fatima's mother and teachers reported that her communication, hygiene, and grooming improved by the end of the intervention. Her mother stated that Fatima became more verbal with strangers, less hesitant, and more assertive. She stopped bedwetting entirely. She became more focused on improving her grades and relations with her brothers and peers. She appeared more cheerful with a more positive self-concept and outlook in life. She developed better eye contact, became less guarded, and exhibited more facial expressions. Her grades improved and her English language acquisition progressed close to the level of her peers. Her IQ was retested and she scored 80 points. Her GAF score increased to 58. Fatima is presently (by the end of the time two and three of testing) still on Zoloft, however she stopped DDAVP nasal spray, as she stopped the bedwetting, and is responding fairly well.

\section{Discussion}

The results supported the effectiveness of the proposed intervention model and the feasibility of conducting larger controlled trial. The changes in psychiatric symptoms and overall functioning occurring over the course of treatment were statistically and clinically significant. The amount of change and functioning displayed by the treated individuals is large enough to be clinically meaningful. The current results, as a preliminary evaluation of the model, strongly support further research with more rigorous designs.

SDTAS model is novel in its adaptation and expansion of different systemic, ecological, and wraparound models and on addressing present, past and chronic traumas and introducing new intervention components (e.g., identity work, and rou-based emotion regulation). Clinicians who worked with the clients in the program reported that open system approach that addresses emerging and continuous events, as well as chronic discriminations was the one of the most effective components of the program. It is worth noting that this program that addressed gender discrimination (GD) (among other discriminations) as one of its components was associated with significant decrease in the existing mental health differences between genders at time three. That may mean that programs that target GD have the potential of significantly reducing the observed differences between genders in mental health.

The wraparound model is widely used on children programs and has previously been shown to be effective with children (e.g., Suter \& Bruns, 2009; Cox et al., 2010; Painter, 2012), adult torture survivors (e.g., McColl et al., 2010, Raghavan, Rasmussen, Rosenfeld, \& Keller, 2013; McFarlane \& Kaplan, 2012, Kira, 2002) and homeless veterans (Smelson et al., 2013). The systemic model has been shown to be effective in Somali refugee children (Ellis et al., 2013). STDAS addresses the unique experiences of refugee children: their primary and secondary, past, present and chronic ongoing traumas in refugee children using an innovative approach. It is flexible and uses the open dynamic system approach that may contribute to its efficacy and address flexibly present, past and continuous chronic traumatic stress. Research found comparable evidence for the effectiveness of both therapies focused on present trauma-focused approach (Classen et al., 2011; Najavits, 2006). A recent 
meta-analysis suggested that the advantage of past trauma focused treatments was small among studies that included clinically complex patients (Gerger, Munder, \& Barth, 2013).

The program was well accepted by the community due to its success. Some families formally complained that their children (clients that do not meet the criteria for the program) were not included. They were referred to alternative programs.

The program was funded at $\$ 150.000$ for the entire period, with about 5555.00 of direct cost per client. The cost-effectiveness of the program seems moderate, considering these clients were unresponsive to treatment as usual. The average monthly treatment cost for such difficult unresponsive cases ranges from $\$ 35000.00$ to over 230000.00 a month in community hospitals (Stensland, Watson, \& Grazier, 2012). Further, using such program within institutional settings in areas of displaced refugees worldwide utilizing well-trained para professionals under direct supervision is worth exploring in future studies to enhance its cost-effectiveness. Meta-analysis concluded that paraprofessionals can be effective in delivering CBT, with outcomes comparable to those of professionals (e.g., Montgomery, Kunik, Wilson, Stanley, \& Weiss, 2010; Papas et al., 2011).

\section{Limitations}

It is difficult to draw firm conclusions about the model effectiveness using a one-group, prospective design. However, the current study provided evidence of feasibility for future more rigorous controlled studies that may use the new sequential multiple assignment randomization (e.g., Lavoria \& Dawson, 2014) to determine the relative effectiveness of each component and to reach a reliable evidence of usefulness and effectiveness of this protocol.

It is difficult to ascertain whether the positive changes are due to the attention the individuals received, to specific aspects of the treatment, or to spontaneous recovery over time. It is unknown which component of this model may have contributed to observed symptom reduction. Further, the number of participants is relatively small and outcomes for individuals who were involved in the intervention other than children (such as parents, teachers) were not assessed. Although therapists received weekly supervision and oversight, treatment adherence was not formally assessed. Some factors that may have contributed to treatment outcome but were not formally assessed include acculturation status and native language.

Nevertheless, the results suggest that the multi-systemic, multi-modal, multi-component ecological interactive open systems model, as a whole, is a promising approach. Significant reduction in PTSD, anxiety, depression and CTD symptoms, and increased functionality occurred in a relatively short time-period in spite of the wide array and severity of trauma profiles in the sample (e.g., torture survivor parents, war in Iraq at the time, intense discrimination and backlash after September 11, 2001, and bullying). As a preliminary study, the current results strongly support further the feasibility of larger research with more rigorous designs.

\section{Practitioner's Points}

- Clinicians should continuously assess and address current, ongoing, chronic and emerging stressors in clients' life, not only his/her past traumas.

- Single-trauma-based manualized interventions may not be as relevant to the multiply traumatized. There is a need to see client trauma exposure through the wider lens of a new developmentally-based trauma framework (DBTF), assess and address the cumulative and trauma proliferation dynamics.

- Practitioners, who work with children, should assess parents' traumas, their mental health status and its potential secondary effects on their children.

- Clinicians, especially who work with minorities and refugee clients should be advocates that help actively address social injustices that impacting their clients.

\section{References}

Altshuler, B. (1981). Modeling of Dose-Response Relationships. Environmental Health Perspectives, 42, $23-27$. http://dx.doi.org/10.1289/ehp.814223

Berger, M., \& Sarnya, Z. (2014). “More Than Skin Deep”: Stress Neurobiology and Mental Health Consequences of Racial Discrimination. Stress, Online First.

Bhugra, D. (2004). Migration and Mental Health. Acta Psychiatrica Scandinavica, 109, 243-258. 
http://dx.doi.org/10.1046/j.0001-690X.2003.00246.x

Bracken, P. J., Giller, J. E., \& Summerfield, D. (1997). Rethinking Mental Health Work with Survivors of Wartime Violence and Refugees. Journal of Refugee Studies, 10, 431-442. http://dx.doi.org/10.1093/jrs/10.4.431

Brookman-Frazee, L., Stahmer, A., Baker-Ericzen, M., \& Tsai, K. (2006). Parenting Interventions for Children with Autism Spectrum and Disruptive Behavior Disorders: Opportunities for Cross-Fertilization. Clinical Child and Family Psychology Review, 9, 181-200. http://dx.doi.org/10.1007/s10567-006-0010-4

Bruns, E. J., Pullmann, M. D., Sather, A., Brinson, R. D., \& Ramey, M. (2015). Effectiveness of Wraparound versus Case Management for Children and Adolescents: Results of a Randomized Study. Administration and Policy in Mental Health and Mental Health Services Research, 42, 309-322. http://dx.doi.org/10.1007/s10488-014-0571-3

Campbell, N. C., Murray, E., Darbyshire, J., Emery, J., Farmer, A., Griffiths, F. et al. (2007). Designing and Evaluating Complex Interventions to Improve Health Care. British Medical Journal, 334, 455-459. http://dx.doi.org/10.1136/bmj.39108.379965.BE

Caspi, A., Houts, R. M., Belsky, D. W., Goldman-Mellor, S. J., Harrington, H., Israel, S. et al. (2014). The p Factor: One General Psychopathology Factor in the Structure of Psychiatric Disorders? Clinical Psychological Science, 2, 119-137. http://dx.doi.org/10.1177/2167702613497473

Chapman, L., Morabito, D., Ladakakos, C., Schreier, H., \& Knudson, M. M. (2001). The Effectiveness of Art Therapy Interventions in Reducing Post-Traumatic Stress Disorder (PTSD) Symptoms in Pediatric Trauma Patients. Art Therapy: Journal of the American Art Therapy Association, 18, 100-104. http://dx.doi.org/10.1080/07421656.2001.10129750

Chu, B. C., Merson, R. A., Zandberg, L. J., \& Areizaga, M. (2012). Calibrating for Comorbidity: Clinical Decision-Making in Youth Depression and Anxiety. Cognitive and Behavioral Practice, 19, 5-16. http://dx.doi.org/10.1016/j.cbpra.2010.10.005

Cicchetti, D., \& Cohen, D. (1995). Perspectives on Developmental Psychopathology. In D. Cicchetti, \& D. Cohen (Eds.), Developmental Psychopathology: Volume 1. Theory and Methods (pp. 3-22). New York: John Wiley.

Classen, C. C., Palesh, O. G., Cavanaugh, C. E., Koopman, C., Kaupp, J. W., Kraemer, H. C. et al. (2011). A Comparison of Trauma-Focused and Present-Focused Group Therapy for Survivors of Childhood Sexual Abuse: A Randomized Controlled Trial. Psychological Trauma: Theory, Research, Practice, and Policy, 3, 84-93. http://dx.doi.org/10.1037/a0020096

Cohen, J. A., Mannarino, A. P., \& Deblinger, E. (2006). Treating Trauma and Traumatic Grief in Children and Adolescents. New York: Guilford Press.

Courtois, C. A., \& Ford, J. D. (2013). Treatment of Complex Trauma: A Sequenced, Relationship-Based Approach. New York: Guilford Press.

Cox, K., Baker, D., \& Wong, M. A. (2010). Wraparound Retrospective Factors Predicting Positive Outcomes. Journal of Emotional and Behavioral Disorders, 18, 3-13. http://dx.doi.org/10.1177/1063426609336955

Ellis, B. H., Miller, A. B., Abdi, S., Barrett, C., Blood, E. A., \& Betancourt, T. S. (2013). Multi-Tier Mental Health Program for Refugee Youth. Journal of Consulting and Clinical Psychology, 81, 129-140. http://dx.doi.org/10.1037/a0029844

Fazel, M., Wheeler, J., \& Danesh, J. (2005). Prevalence of Serious Mental Disorder in 7000 Refugees Resettled in Western Countries: A Systematic Review. The Lancet, 365, 1309-1314. http://dx.doi.org/10.1016/S0140-6736(05)61027-6

Figley, C. R. (1988). A Five-Phase Treatment of Post-Traumatic Stress Disorder in Families. Journal of Traumatic Stress, 1 , 127-141. http://dx.doi.org/10.1002/jts.2490010109

Ford, J. D., \& Courtois, C. A. (Eds.) (2013). Treating Complex Traumatic Stress Disorder in Children and Adolescents. New York: Guilford Press.

Ford, J. D., \& Russo, E. (2006). Trauma-Focused, Present-Centered, Emotional Self-Regulation Approach to Integrated Treatment for Posttraumatic Stress and Addiction: Trauma Adaptive Recovery Group Education and Therapy (TARGET). American Journal of Psychotherapy, 60, 335-355.

Gaertner, S. L., \& Dovidio, J. F. (2005). Categorization, Re-Cateogrization and Intergroup Bias. In J. F. Dovidio, P. Glick, \& L. Rudman (Eds.), Reflecting on the Nature of Prejudice (pp. 71-88). Philadelphia, PA: Psychology Press. http://dx.doi.org/10.1002/9780470773963.ch5

Gerger, H., Munder, T., \& Barth, J. (2013). Specific and Nonspecific Psychological Interventions for PTSD Symptoms: A Meta-Analysis with Problem Complexity as a Moderator. Journal of Clinical Psychology, Advance Online Publication.

Goodman, R. D., \& West-Olatunji, C. A. (2009). Applying Critical Consciousness: Culturally Competent Disaster Response Outcomes. Journal of Counseling \& Development, 87, 458-465. http://dx.doi.org/10.1002/j.1556-6678.2009.tb00130.x

Goodman, R., \& Gorski, P. C. (Eds.) (2015). Decolonizing “Multicultural” Counseling through Social Justice (International and Cultural Psychology). New York: Springer. http://dx.doi.org/10.1007/978-1-4939-1283-4

Grist, R., \& Cavanagh, K. (2013). Computerized Cognitive Behavioral Therapy for Common Mental Health Disorders, What 
Works, for Whom under What Circumstances? A Systematic Review and Meta-Analysis. Journal of Contemporary Psychotherapy, 43, 243-251. http://dx.doi.org/10.1007/s10879-013-9243-y

Gunderson, J. G. (1978). Defining the Therapeutic Process in Psychiatric Milieus. Psychiatry: Journal for the Study of Interpersonal Processes, 41, 327-335.

Huang, D., \& Cho, J. (2009). Academic Enrichment in High Functioning Homework After-School Programs. Journal of Research in Childhood Education, 23, 382-392. http://dx.doi.org/10.1080/02568540909594668

IRC Commission on Iraqi Refugees Report (2009). Iraqi Refugees in the US in Dire Straits. http://www.rescue.org/sites/default/files/resource-file/irc_report_iraqcommission.pdf

Keeley, J. W., Chmielewski, M. S., \& Bagby, R. M. (2015). Interaction Effects in Comorbid Psychopathology. Comprehensive Psychiatry, 60, 35-39. http://dx.doi.org/10.1016/j.comppsych.2015.04.008

Kessler, R. C., Chiu, W. T., Demler, O., \& Walters, E. E. (2005). Prevalence, Severity, and Comorbidity of Twelve-Month DSM-IV Disorders in the National Comorbidity Survey Replication (NCSR). Archives of General Psychiatry, 62, $617-627$. http://dx.doi.org/10.1001/archpsyc.62.6.617

Kira, I. (2002). Torture Assessment and Treatment: The Wraparound Approach. Traumatology, 8, 54-86. http://dx.doi.org/10.1177/153476560200800203

Kira, I. (2004). Secondary Trauma in Treating Refugee Survivors of Torture: Assessing and Responding to Secondary Traumatization in the Survivors' Families. Torture, 14, 38-44.

Kira, I. (2013). Interventions with Continuous Traumatic Stress of Discrimination in Youth. Proceedings of the International Symposium on Arab Youth: Developmental Pathways for Identity, Windsor, 29-30 May 2013.

http://scholar.uwindsor.ca/arabyouthsymp/conference_presentations/presentations2/3/

Kira, I. A. (2001). Taxonomy of Trauma and Trauma Assessment. Traumatology, 7, 73-86. http://dx.doi.org/10.1177/153476560100700202

Kira, I. A. (2010). Etiology and Treatments of Post-Cumulative Traumatic Stress Disorders in Different Cultures. Traumatology: An International Journal, 16, 128-141. http://dx.doi.org/10.1177/1534765610365914

Kira, I. A., Amer, M. M., \& Wrobel, N. H. (2014). Arab Refugees: Trauma, Resilience, and Recovery. In S. C. Nassar-McMillan, K. J. Ajrouch, \& J. Hakim-Larson (Eds.), Biopsychosocial Perspectives on Arab Americans: Culture, Development, and Health (pp.175-195). New York: Springer.

Kira, I. A., Ashby J. S., Lewandowski, L., Alawneh, A. W. N., Mohanesh, J., \& Odenat, L. (2013). Advances in Continuous Traumatic Stress Theory: Traumatogenic Dynamics and Consequences of Intergroup Conflict: The Palestinian Adolescent's Case. Psychology, 4, 396-409. http://dx.doi.org/10.4236/psych.2013.44057

Kira, I. A., Ashby, J. S., Odenat, L., \& Lewandowski, L. (2013). The Mental Health Effects of Torture Trauma and Its Severity: A Replication and Extension. Psychology, 4, 472-482. http://dx.doi.org/10.4236/psych.2013.45067

Kira, I. A., Fawzi, M. H., \& Fawzi, M. M. (2013). The Dynamics of Cumulative Trauma and Trauma Types in Adults Patients with Psychiatric Disorders: Two Cross-Cultural Studies. Traumatology, 19, 179-195.

http://dx.doi.org/10.1177/1534765612459892

Kira, I. A., Lewandowsi, L., Templin, T., Ramaswamy, V., Ozkan, B., \& Mohanesh, J. (2010). The Effects of Perceived Discrimination and Backlash on Iraqi Refugees' Physical and Mental Health. Journal of Muslim Mental Health, 5, 59-81. http://dx.doi.org/10.1080/15564901003622110

Kira, I. A., Lewandowsk, L., Templin, T., Ramaswamy, V., Ozkan, B., \& Mohanesh, J. (2008). Measuring Cumulative Trauma Dose, Types and Profiles Using a Development-Based Taxonomy of Trauma. Traumatology, 14, 62-87. http://dx.doi.org/10.1177/1534765608319324

Kira, I. A., Lewandowski, L., Ashby, J. S., Somers, C., Chiodo, L., \& Odenat, L. (2014). Does Bullying Victimization Suppress IQ? The Effects of Bullying Victimization on IQ in Iraqi and African American Adolescents: A Traumatology Perspective. Journal of Aggression, Maltreatment, and Trauma, 23, 431-453. http://dx.doi.org/10.1080/10926771.2014.904463

Kira, I. A., Omidy, A. Z., \& Ashby, J. S. (2014). Cumulative Trauma, Appraisal and Coping in Palestinian and American Indian Adults: Two Cross-Cultural Studies. Traumatology: An International Journal, 20, 119-133. http://dx.doi.org/10.1037/h0099397

Kira, I. A., Omidy, A. Z., Fawzi, M., Rice, K. G., Fawzi, M., Lewandowski, L., \& Bujold-Bugeaud, M. (2015). Are the Negative Mental Health Effects of Gender Discrimination (GD) Salient across Cultures? Does Self-Esteem Mediate These Effects: GD as a Continuous Traumatic Stress and the Pathways to Its Negative Dynamics? Psychology, 6, 93-116. http://dx.doi.org/10.4236/psych.2015.61009

Kira, I. A., Smith, I., Lewandowski, L., \&Templin, T. (2010). The Effects of Perceived Gender Discrimination on Refugee Torture Survivors: A Cross-Cultural Traumatology Perspective. Journal of the American Psychiatric Nurses Association, 
16, 299-306. http://dx.doi.org/10.1177/1078390310384401

Kira, I. A., Templin, T., Lewandowski, L., Ashby, J. S., Oladele, A., \& Odenat, L. (2012). Cumulative Trauma Disorder Scale (CTD): Two Studies. Psychology, 3, 643-656. http://dx.doi.org/10.4236/psych.2012.39099

Kira, I. A., Templin, T., Lewandowski, L., Clifford, D., Wiencek, P., Hammad, A., \& Al-Haidar, A. M. (2006). The Effects of Torture: Two Community Studies. Peace and Conflict: Journal of Peace Psychology, 12, 205-228. http://dx.doi.org/10.1207/s15327949pac1203_1

Kira, I. A., Wroble, N. H. (In Press). Trauma: Stress, Coping, and Emerging Treatment Models. In M. M. Amer, \& G. H. Awad (Eds.), Handbook of Arab American Psychology. New York: Routledge.

Kira, I., \& Tummala-Narra, P. (2014). Psychotherapy with Refugees: Emerging Paradigms. Journal of Loss and Trauma: International Perspectives on Stress \& Coping, Online First Publication.

Kira, I., Alawneh, A., Aboumediene, S., Lewandowski, L., \& Laddis, A. (2014). Dynamics of Oppression and Coping from Traumatology Perspective: The Example of Palestinian Youth. Peace and Conflict: Journal of Peace Psychology, 20, 385411. http://dx.doi.org/10.1037/pac0000053

Kira, I., Ashby, J. S., Omidy, A. Z., \& Lewandowski, L. Current, Continuous, and Cumulative Trauma-Focused Cognitive Behavior Therapy (CCC-TF-CBT). Journal of Mental Health Counseling, Invited Paper Submitted for Publication, in Press.

Kira, I., Ashby, J., Lewandowski, L., Smith, I., \& Odenat, L. (2012). Gender Inequality and Its Effects in Females Torture Survivors. Psychology, 3, 352-363. http://dx.doi.org/10.4236/psych.2012.34050

Kira, I., Hammad, A., Lewandowski, L., Templin, T., Ramswamy, V., Ozkan, B., \& Mohanesh, J. (2007). The Physical and Mental Status of Iraqi Refugees and Its Etiology. Ethnicity \& Disease, 17, 79-82.

Kira, I., Lewandowki, L., Chiodo, L., \& Ibrahim, A. (2014). Advances in Systemic Trauma Theory: Traumatogenic Dynamics and Consequences of Backlash as a Multi-Systemic Trauma on Iraqi Refugee Muslim Adolescents. Psychology, 5, 389-412. http://dx.doi.org/10.4236/psych.2014.55050

Kira, I., Templin, T., Lewandowski, L., Ramaswamy, V., Ozkan, B., \& Mohanesh, J. (2008). The Physical and Mental Health Effects of Watching Reports of the Iraqi War on Iraqi Refugees. Journal of Muslim Mental Health, 3, $193-215$. http://dx.doi.org/10.1080/15564900802487592

Krueger, R. F., \& Markon, K. E. (2006). Reinterpreting Comorbidity: A Model-Based Approach to Understanding and Classifying Psychopathology. Annual Review of Clinical Psychology, 2, 111-133.

http://dx.doi.org/10.1146/annurev.clinpsy.2.022305.095213

Laceulle, O., Vollebergh, W., \& Ormel, J. (2015). The Structure of Psychopathology in Adolescence: Replication of a General Psychopathology Factor in the TRAILS Study. Clinical Psychological Science, On Line First. http://dx.doi.org/10.1177/2167702614560750

Lambert, J. E., Engh, R., Hasbun, A., \& Holzer, J. (2012). Impact of Posttraumatic Stress Disorder on the Relationship Quality and Psychological Distress of Intimate Partners: A Meta-Analytic Review. Journal of Family Psychology, 26, $729-737$. http://dx.doi.org/10.1037/a0029341

Laska, K. M., Gurman, A. S., \& Wampold, B. E. (2014). Expanding the Lens of Evidence-Based Practice in Psychotherapy: A Common Factors Perspective. Psychotherapy, 51, 467-481. http://dx.doi.org/10.1037/a0034332

Lavoria, P. W., \& Dawson, R. (2014). Introduction to Dynamic Treatment Strategies and Sequential Multiple Assignment Randomization. Clinical Trials, 11, 393-399. http://dx.doi.org/10.1177/1740774514527651

Levitt, J. T., Malta, L. S., Martin, A., Davis, L., \& Cloitre, M. (2007). The Flexible Application of a Manualized Treatment for PTSD Symptoms and Functional Impairment Related to the 9/11 World Trade Center Attack. Behaviour Research \& Therapy, 45, 1419-1433. http://dx.doi.org/10.1016/j.brat.2007.01.004

Lewis, G., Rice, F., Harold, G. T., Collishaw, S., \& Thapar, A. (2011). Investigating Environmental Links between Parent Depression and Child Depressive/Anxiety Symptoms Using an Assisted Conception Design. Journal of American Academy of Child and Adolescent Psychiatry, 50, 451-459. http://dx.doi.org/10.1016/j.jaac.2011.01.015

Liu, S., Huang, J. L., \& Wang, M. (2014). Effectiveness of Job Search Interventions: A Meta-Analytic Review. Psychological Bulletin, 140, 1009-1041. http://dx.doi.org/10.1037/a0035923

Lovibond, S. H., \& Lovibond, P. F. (1995). Manual for the Depression Anxiety Stress Scales. Sydney: Psychology Foundation of Australia.

Lyman, D. R., Kurtz, M. M., Farkas, M., George, P., Dougherty, R. H., Daniels, A. S., Ghose, S., \& Delphin-Rittmon, M. (2014). Skill Building: Assessing the Evidence. Psychiatric Services, 65, 727-738. http://dx.doi.org/10.1176/appi.ps.201300251

Mallinckrodt, B., Miles, J. R., \& Levy, J. J. (2014). The Scientist-Practitioner-Advocate Model: Addressing Contemporary Training Needs for Social Justice Advocacy. Training and Education in Professional Psychology, Advance Online Publi- 
cation. http://dx.doi.org/10.1037/tep0000045

McColl, H., Higson-Smith, C., Gjerding, S., Omar, M. H., Rahman, B. A., Hamed, M., \& Awad, Z. (2010). Research Rehabilitation of Torture Survivors in Five Countries: Common Themes and Challenges. International Journal of Mental Health Systems, 4, 1-10.

McEvoy, P. M., Nathan, P., \& Norton P. J. (2009). Efficacy of Transdiagnostic Treatments: A Review of Published Outcome Studies and Future Research Directions. Journal of Cognitive Psychotherapy, 23, 20-33. http://dx.doi.org/10.1891/0889-8391.23.1.20

McFarlane, C. A., \& Kaplan, I. (2012). Evidence-Based Psychological Interventions for Adult Survivors of Torture and Trauma: A 30-Year Review. Transcultural Psychiatry, 49, 539-567. http://dx.doi.org/10.1177/1363461512447608

McGhee, S. A., Groff, D. G., \& Russoniello, C. V. (2005). We Care Too: Providing Community-Based Therapeutic Recreation Services for Youth with Emotional and Behavioral Disorders. Therapeutic Recreation Journal, 39, 32-46.

Montgomery, E. C., Kunik, M. E., Wilson, N., Stanley, M. A., \& Weiss, B. (2010). Can Paraprofessionals Deliver Cognitive-Behavioral Therapy to Treat Anxiety and Depressive Symptoms? Bulletin of Menninger Clinic, 74, 45-62. http://dx.doi.org/10.1521/bumc.2010.74.1.45

Moses, E. B., \& Barlow, H. (2006). A New Unified Treatment Approach for Emotional Disorders Based on Emotion Science. Current Directions in Psychological Science, 15, 146-150. http://dx.doi.org/10.1111/j.0963-7214.2006.00425.x

Murray, L. K., Cohen, J. A., \& Mannarino, A. P. (2013). Trauma-Focused Cognitive Behavioral Therapy for Youth Who Experience Continuous Traumatic Exposure. Peace and Conflict: Journal of Peace Psychology, 19, 180-195. http://dx.doi.org/10.1037/a0032533

Najavits, L. M. (2002). Seeking Safety: A Treatment Manual for PTSD and Substance Abuse. New York: Guilford Press.

Najavits, L. M. (2006). Present versus Past-Focused Therapy for Posttraumatic Stress Disorder/Substance Abuse. Brief Treatment and Crisis Intervention, 6, 248-254. http://dx.doi.org/10.1093/brief-treatment/mhl005

Nickerson, A., Bryant, R. A., Silove, D., \& Steel, Z. (2011). A Critical Review of Psychological Treatments of Posttraumatic Stress Disorder in Refugees. Clinical Psychology Review, 31, 399-417. http://dx.doi.org/10.1016/j.cpr.2010.10.004

North, C. S., Pollio, D. E., Hong, B. A., Pandya, A., Smith, R., \& Pfefferbaum, B. (2015). The Post-Disaster Prevalence of Major Depression Relative to PTSD in Survivors of the 9/11 Attacks on the World Trade Center Selected from Affected Workplaces. Comprehensive Psychiatry, 60, 119-125. http://dx.doi.org/10.1016/j.comppsych.2015.02.009

Painter, K. (2012). Outcomes for Youth with Severe Emotional Disturbance: A Repeated Measures Longitudinal Study of a Wraparound Approach of Service Delivery in Systems of Care. Child \& Youth Care Forum, 41, 407-425. http://dx.doi.org/10.1007/s10566-011-9167-1

Papas, R. K., Sidle, J. E., Gakinya, B. N., Baliddawa, J. B., Martino, S., Mwaniki, M. M. et al. (2011). Treatment Outcomes of a Stage 1 Cognitive-Behavioral Trial to Reduce Alcohol Use among Human Immunodeficiency Virus Infected Out-Patients in Western Kenya. Addiction, 106, 2156-2166. http://dx.doi.org/10.1111/j.1360-0443.2011.03518.x

Pascoe, E. A., \& Richman, S. L. (2009). Perceived Discrimination and Health: A Meta-Analytic Review. Psychological Bulletin, 135, 531-554. http://dx.doi.org/10.1037/a0016059

Pearlin, L. I., Aneshensel, C. S., \& Leblanc, A. J. (1997). The Forms and Mechanisms of Stress Proliferation: The Case of AIDS Caregivers. Journal of Health and Social Behavior, 38, 223-236. http://dx.doi.org/10.2307/2955368

Radloff, L. S. (1991). The Use of the Center for Epidemiologic Studies Depression Scale in Adolescents and Young Adults. Journal of Youth and Adolescence, 20, 149-166. http://dx.doi.org/10.1007/BF01537606

Raghavan, S., Rasmussen, A., Rosenfeld, B., \& Keller, A. S. (2013). Correlates of Symptom Reduction in Treatment-Seeking Survivors of Torture. Psychological Trauma: Theory, Research, Practice, and Policy, 5, 377-393. http://dx.doi.org/10.1037/a0028118

Ruf, M., Schauer, M., Neuner, F., Catani, C., Schauer, E., \& Elbert, T. (2010). Narrative Exposure Therapy for 7-to 16-YearOlds: A Randomized Controlled Trial with Traumatized Refugee Children. Journal of Traumatic Stress, 23, 437-445. http://dx.doi.org/10.1002/jts.20548

Saxe, G. N., Ellis, B. H., \& Kaplow, J. B. (2007). Collaborative Treatment of Traumatized Children and Teens: The Trauma Systems Therapy Approach. New York: Guilford Press.

Scheepers, D., Spears, R., Manstead, A. S., \& Doosje, B. (2009). The Influence of Discrimination and Fairness on Collective Self-Esteem. Personality and Social Psychology Bulletin, 35, 505-515. http://dx.doi.org/10.1177/0146167208329855

Selten, J., Cantor-Graae, E., \& Kahn, R. (2007). Migration and Schizophrenia. Current Opinion in Psychiatry, 20, 111-115. http://dx.doi.org/10.1097/YCO.0b013e328017f68e

Smelson, D. A., Kline, A., Kuhn, J., Rodrigues, S., O’Connor, K., Fisher, W. et al. (2013). A Wraparound Treatment Engagement Intervention for Homeless Veterans with Co-Occurring Disorders. Psychological Services, 10, 161-167. http://dx.doi.org/10.1037/a0030948 
Springer, K., \& Diffily, D. (2012). The Relationship between Intensity and Breadth of After-School Program Participation and Academic Achievement: Evidence from a Short-Term Longitudinal Study. Journal of Community Psychology, 40, 785-798. http://dx.doi.org/10.1002/jcop.21478

Stensland, M., Watson, P. R., \& Grazier, K. L. (2012). An Examination of Costs, Charges, and Payments for Inpatient Psychiatric Treatment in Community Hospitals. Psychiatric Services, 63, 666-671. http://dx.doi.org/10.1176/appi.ps.201100402

Summerfield, D. (1999). A Critique of Seven Assumptions behind Psychological Trauma Programs in War-Affected Areas. Social Science and Medicine, 48, 1449-1462. http://dx.doi.org/10.1016/S0277-9536(98)00450-X

Suter, J. C., \& Bruns, E. J. (2009). Effectiveness of the Wraparound Process for Children with Emotional and Behavioral Disorders: A Meta-Analysis. Clinical Child and Family Psychology Review, 12, 336-351. http://dx.doi.org/10.1007/s10567-009-0059-y

Tabachnick, B. G., \& Fidell, L. S. (2013). Using Multivariate Statistics (6th ed.). Boston, MA: Pearson.

Terr, L. C. (1991). Childhood Traumas: An Outline and Overview. American Journal of Psychiatry, 148, 10-20. http://dx.doi.org/10.1176/ajp.148.1.10

Tong, H. (1978). On a Threshold Model. In: C. Chen (Ed.), Pattern Recognition and Signal Processing (pp. 575-586). Alphen aan den Rijn, The Netherlands: Sijthoff \& Noordhoff. http://dx.doi.org/10.1007/978-94-009-9941-1_24

Travagina, G., Margolaa, D., \&. Revensonb, T. A. (2015). How Effective Are Expressive Writing Interventions for Adolescents? A Meta-Analytic Review. Clinical Psychology Review, 36, 42-55. http://dx.doi.org/10.1016/j.cpr.2015.01.003

Weathers, F. W., Keane, T. M., \& Davidson, J. R. T. (2001). Clinician-Administered PTSD Scale: A Review of the First Ten Years of Research. Depression and Anxiety, 13, 132-156. http://dx.doi.org/10.1002/da.1029

Weinfurt, K. (2000). Repeated Measures Analysis: ANOVA, MANOVA, and HLM. In L. Grimm, \& R. Yarnold (Eds.), Reading and Understanding MORE Multivariate Statistics (pp. 317-361). Washington DC: American Psychological Association.

Zhang, L., Wang, H. J., \& Zhu1, Z. (2014). Testing for Change Points Due to Covariate Threshold in Quantile Regression. Statistica Sinica, 24, 1859-1877. 